\title{
Polylactic acid (PLA) based green composites reinforced pineapple leaf fibres: evaluation of processing and tensile performance
}

\author{
Jedsada Chaishome ${ }^{1, *}$ and Suriyan Supapvanich ${ }^{2}$ \\ ${ }^{1}$ Food Engineering Department, Faculty of Engineering, King Mongkut's Institute of Technology Ladkrabang, Bangkok, Thailand \\ ${ }^{2}$ Department of Agricultural Education, Faculty of Industrial Education and Technology, King Mongkut's Institute of Technology \\ Ladkrabang, Bangkok, Thailand
}

\begin{abstract}
This paper reports on a study of the compression moulding and the vacuum forming of unidirectional pineapple leaf fibres/polylactic acid composites and the influence of process variables on the tensile properties of the material. The characterisation of the micro and meso structures of the pineapple leaf fibres is reported. The effect of consolidation temperature on the fibre thermal stability and the tensile properties of the composites is investigated. The results show that vacuum forming was found to be preferable process with high stiffness modulus and UTS of the composites, compared to compression moulding. The insignificant detrimental effect of $165^{\circ} \mathrm{C}$ high consolidation temperature was observed. Finally, the fibre thermal degradation seems to dominate the composite tensile performance over its interfacial quality between the fibre and the matrix.
\end{abstract}

\section{Introduction}

There has been a sustainable agriculture itinerary toward short product life cycle made from renewable or biodegradable materials. For this season, academic research has been shifting from synthetic materials to natural materials, like fibres and bio-plastic composites [1-3]. Furthermore, the natural material offers several advantages i.e., light weighting, eco-friendliness and safety from hazards $[4,5]$.

Since 2006, environmental legislation in Europe and Japan has increased the pressure to reuse or to use renewable materials in the manufacture of vehicles [6]. For that reason, and the general drive toward sustainability, natural fibre reinforced polymer composite materials are of increasing interest in the automotive industry. They are also attracting interest for many other application areas including tribology, piping and electronic devices [7-9].

Natural fibres, such as pineapple leaf, ramie and hemp, are low density and can be used as the composite reinforcement, especially non-structural applications $[6$, 7]. Even though their tensile strength is low, compared to the E-glass fibres, it can compete in terms of specific properties [10-12].

Notwithstanding, their thermal stability of hemicellulose consisted of plant fibres limits composite properties after high temperature thermoplastic forming. The various natural constituents of plant fibre result in poor composite performance due to their low thermal degradation [13-15]. It depends on a number of factors namely heat rate, temperature and chemical composition of materials. Flax retains its strength at $170{ }^{\circ} \mathrm{C}$ for 2 hours while that of $200{ }^{\circ} \mathrm{C}$ for half an hour, for instance $[14,16]$. In addition, polymers (as matrix materials) are limited from low thermal decomposition temperature of the plant fibres at high melted temperature processing. On the other hand, high viscosity melted thermoplastic property leads to low consolidation with high void content of composite, especially short dwelling period. Natural materials could generate a number of volatile products from their chemical constituents during high temperature and trap in the laminates as voidage[17].

\section{Materials and experimental Method}

\subsection{Materials}

Polylactic acid (PLA) and pine apple leaf fibrers are used in this investigation. PLA in a pellet form, supplied by Naturework Co., Ltd., is used as the matrix and the reinforcement is a unidirectional (UD) pineapple leaf fibres. Before the moulding studies, the fibres were fully characterised to determine, fibre diameter, fibre apparent density and fibre hydration levels.

\subsection{Composite manufacturing}

The UD pineapple leaf fibre/PLA composites were processed by isothermal film stacking of $40 \%$ fibre volume fraction $\left(\mathrm{V}_{\mathrm{f}}\right)$ with compression moulding and vacuum forming process.

\footnotetext{
* Corresponding author: jedsada.ch@,kmitl.ac.th
} 


\subsection{Thermogravimetric analysis}

Thermal stability of pineapple leaf fibres was studied by thermogravimetric analysis. The samples were dried at $60{ }^{\circ} \mathrm{C}$ for 8 hours and were vacuum packed before performing. The fibres were weighted $10 \mathrm{mg}$ and test using thermogravimetric (TG) technique to obtain a differential thermogravimetric (DTG) curves. The examination was conducted with a thermal analyzer setaram (Labsys evo TG/DTA, TG/DSC), under argon atmosphere. A heating process of room temperature to $600{ }^{\circ} \mathrm{C}$ at $10{ }^{\circ} \mathrm{C} / \mathrm{min}$ of heating rate was used with an argon flow rate of $20 \mathrm{ml} / \mathrm{min}$. Argon does not react with all materials as an inert gas.

\subsection{Tensile test}

Single fibres were performed tensile properties, according to ISO 11566: 1996. A TA XTplus of Texture Analyzer was used to examine 20 replicated samples with $2.5 \mathrm{~mm} / \mathrm{min}$ of cross head speed. Each fibre crosssectional area was calculated from each optical micrograph with image processing (ImageJ open source program).

The composite samples were examined their tensile perform according to ISO527-5:2009 (using an Instron universal testing machine). An extensometer gauge length of $50 \mathrm{~mm}$ at a cross head speed of $2 \mathrm{~mm} / \mathrm{min}$ attached to ten replicated from each plaque test.

\section{Results and discussion}

\subsection{Characterisation of the pineapple leaf fibres}

The pineapple leaf fibre bundles were shown in Fig. 1 and single fibres were shown in Fig. 2. Each single fibre is not uniform shape. The mean equivalent diameter is 62.27 micrometres. A fibre apparent density of 1.32 $\mathrm{g} / \mathrm{cm}^{3}$ and the average moisture content at the initial condition of $11.24 \%$ for arbitrary storage RH were examined. Fig. 3 shows the stress-strain curves of pineapple leaf single fibre.

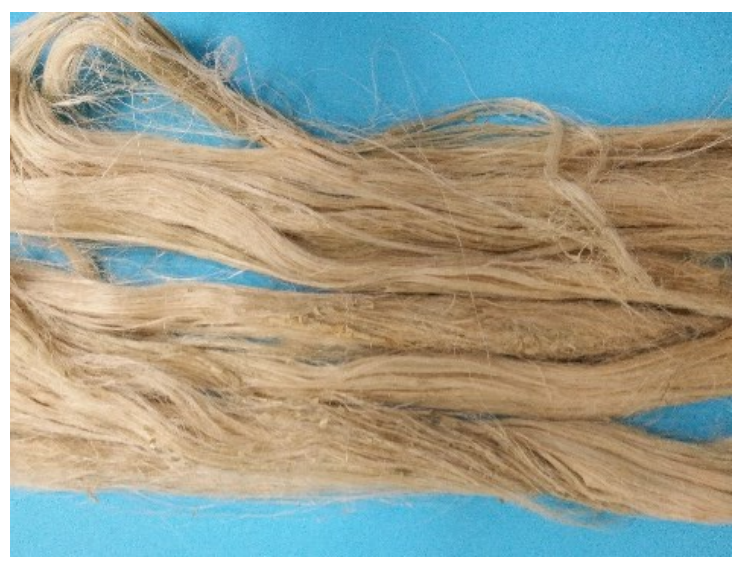

Fig. 1 The pineapple leaf fibre bundles.

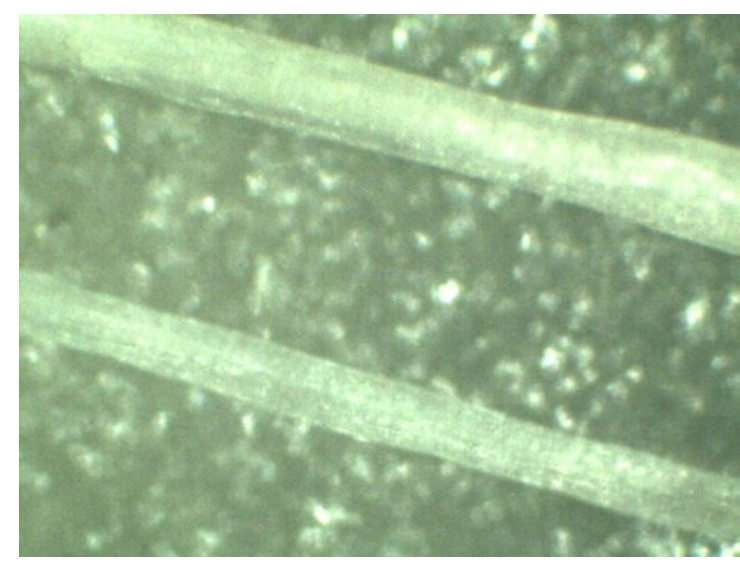

Fig. 2 The pineapple leaf single fibres.

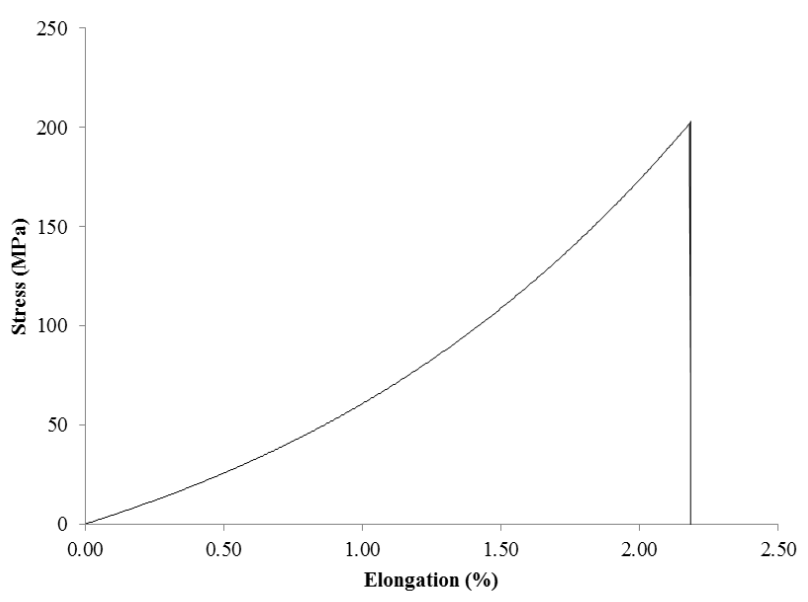

Fig. 3 Stress-strain curves of pineapple leaf single fibre.

\subsection{Effect of temperature on the Thermal Stability of Fibres}

Fig. 4 shows the differential thermogravimetric (DTG) peak between $30^{\circ} \mathrm{C}$ and $600{ }^{\circ} \mathrm{C}$. A small peak (between $45^{\circ} \mathrm{C}$ and $120^{\circ} \mathrm{C}$ ) attributed to the water mass loss of the moist fibres. There is a shoulder peak (between $230{ }^{\circ} \mathrm{C}$ and $270{ }^{\circ} \mathrm{C}$ ) attributed to hemi-cellulose and pectin degradation. A sharp peak at $350{ }^{\circ} \mathrm{C}$ attributed to cellulose degradation.

The DTG and the second time derivatives $\left(\mathrm{D}^{2} \mathrm{TG}\right)$ curves were used to evaluate the initial decomposition temperature $\left(T_{0}\right)$ of pineapple leaf fibres as described in Yao, et al.'s article[18]. The results from the thermal stability study reveal that the pineapple leaf fibre are stable until $250^{\circ} \mathrm{C}$ at a heating rate of $10^{\circ} \mathrm{C} / \mathrm{min}$. Nevertheless, TGA only shows the dynamic heating results $\left(\sim 40\right.$ to $200^{\circ} \mathrm{C}$ for 18 minutes). The result of quasi-static composite processing $\left(\sim 40\right.$ to $200^{\circ} \mathrm{C}$ for about 300 minutes) could show a much higher thermal degradation effect and the temperature limit of that is therefore likely to be below $250^{\circ} \mathrm{C}$, resulting in a likely compromising of the mechanical performance of the fibres. 


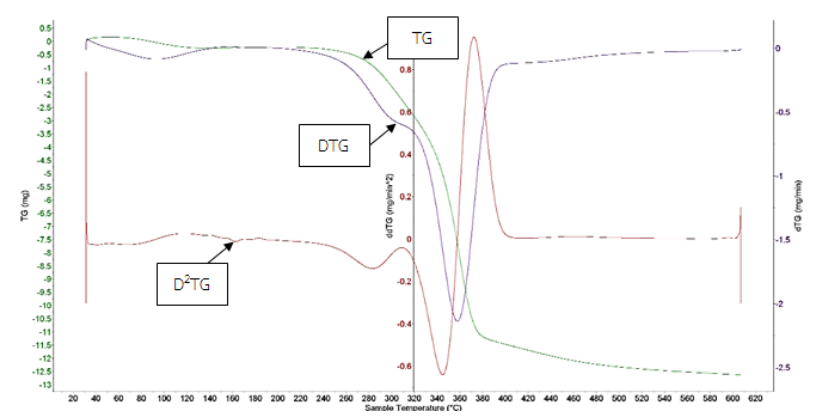

Fig. 4 The differential thermogravimetric (DTG) curves of the pineapple leaf fibre bundles.

\subsection{Effect of processing on the tensile performance of composites}

Tensile performance of $40 \% \mathrm{~V}_{\mathrm{f}}$ UD pineapple leaf /PLA composites, are compared in Figs. 5. The materials processed with compression moulding of $50 \mathrm{kPa}$ at 165 , 180 and $190^{\circ} \mathrm{C}$ for 3,5 and 7 mins were performed. The materials processed with vacuum forming at 165,180 and $190^{\circ} \mathrm{C}$ for 30,60 and 90 mins were examined.

Both modulus and UTS of the composites decrease with the dwelling time increase. The UTS of the compression moulding material is lower than that of the vacuum forming material. The weaker performance of the compression moulding material could be attributed to the higher void content level of the composite, caused by low consolidation time. Fig. 6 shows a micrograph of fibre-matrix interfaces.

Voidage presences in Fig. 6 expose their weak interfacial bonding between the fibres and the matrix due to inadequate consolidation time.

\section{Conclusions}

- Vacuum forming was found be preferable process with high stiffness modulus and UTS of the composites, compared to compression moulding.

- The insignificant detrimental effect of $165^{\circ} \mathrm{C}$ high consolidation temperature was observed.

- The fibre thermal degradation could dominate the composite tensile performance over their poor interfacial bonding effects.

\section{Acknowledgements}

The authors gratefully acknowledge the BiodiversityBased Economy Development Office (Puplic Orgaization) (BEDO) for research funding and the department of Industrial Engineering, Faculty of Engineering, King Mongkut's Institute of Technology Ladkrabang, Bangkok, Thailand for the universal testing machine support.

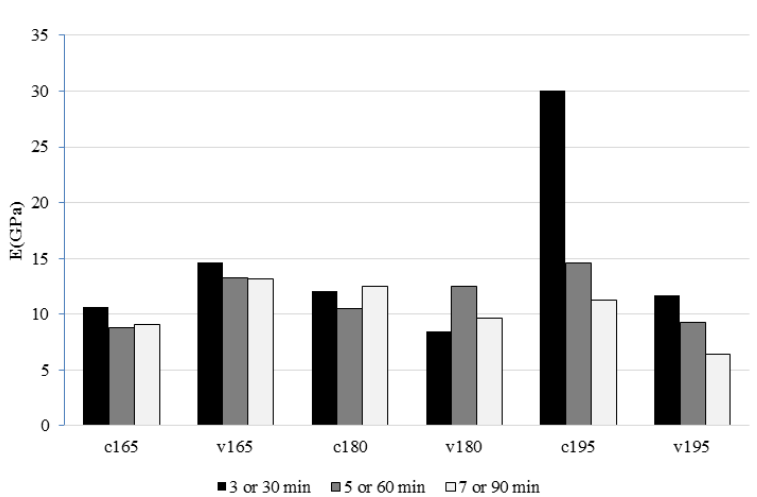

(a)

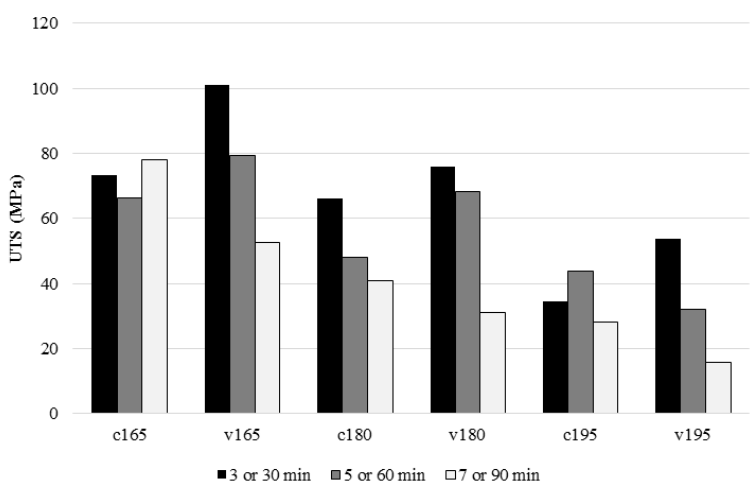

(b)

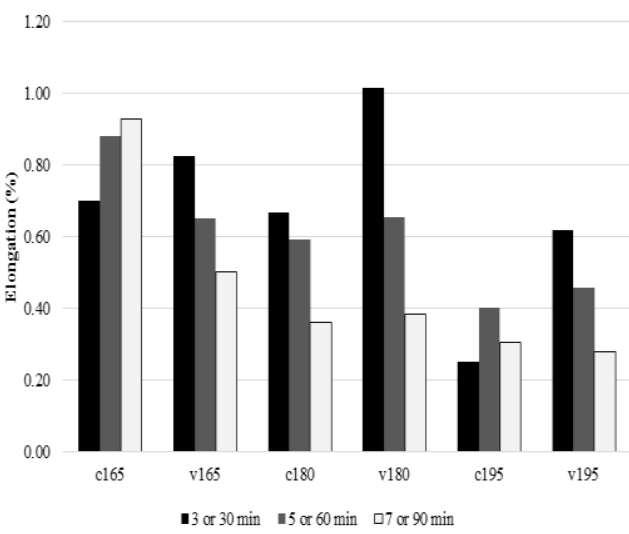

(c)

Fig. 5 (a) Stiffness modulus (E) of $40 \% \mathrm{~V}_{\mathrm{f}}$ UD pineapple leaf /PLA composites (b) Ultimate tensile strength (UTS) of $40 \% \mathrm{~V}_{\mathrm{f}} \mathrm{UD}$ pineapple leaf /PLA composites

(c) Percentage of composite elongation at break of $40 \% \mathrm{~V}_{\mathrm{f}} \mathrm{UD}$ pineapple leaf/PLA composites

* c165 is compression moulding process of $50 \mathrm{MPa}$ at $165^{\circ} \mathrm{C}$ of $40 \% \mathrm{~V}_{\mathrm{f}} \mathrm{UD}$ pineapple leaf /PLA composites

* v165 is vacuum forming process at $165^{\circ} \mathrm{C}$ of $40 \% \mathrm{~V}_{\mathrm{f}}$ UD pineapple leaf /PLA composites. 


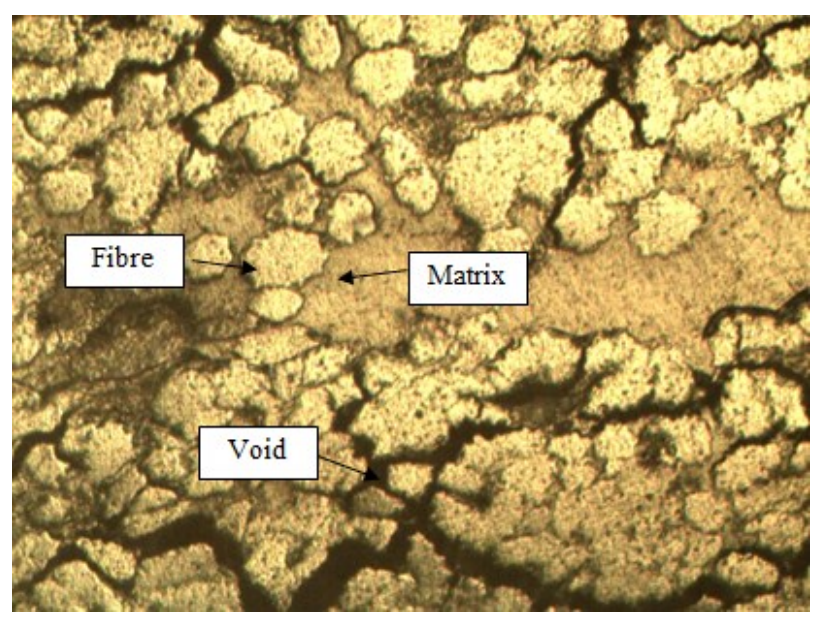

Fig. 6 poor-impregnated laminate with high void content of the pineapple leaf fibre bundles

\section{References}

1. Agopyan, V., et al., Developments on vegetable fibre-cement based materials in Sao Paulo, Brazil: an overview. Cement and Concrete Composites, 2005. 27(5): p. 527-536.

2. Alavudeen, A., et al., Review of natural fiber woven composite. Reviews on Advanced Materials Science, 2011. 27(2): p. 146-150.

3. Chaishome, J. and S. Rattanapaskorn. The influence of alkaline treatment on thermal stability of flax fibres. in IOP Conference Series: Materials Science and Engineering. 2017.

4. Bodig, J. and B.A. Jayne, Mechanics of wood and wood composities. Reprint ed. with corrections. ed. 1993, Malabar, Fla.: Krieger Pub.

5. John, M.J. and S. Thomas, Biofibres and biocomposites. Carbohydrate Polymers, 2008. 71(3): p. 343-364.

6. Holbery, J. and D. Houston, Natural-fiberreinforced polymer composites in automotive applications. JOM Journal of the Minerals, Metals and Materials Society, 2006. 58(11): p. 80-86.

7. El-Tayeb, N.S.M., A study on the potential of sugarcane fibers/polyester composite for tribological applications. Wear, 2008. 265(12): p. 223-235.

8. Rao, V.A., A. Satapathy, and S.C. Mishra. Polymer composites reinforced with short fibers obtained from poultry feathers. in Proceeding of International and INCCOM-6 Future Trends in Composite Materials and Processing. 2007. Kanpur.

9. Chang, K.H. and P.W. Richard, Development of a bio-based composite material from soybean oil and keratin fibers. Journal of Applied Polymer Science, 2005. 95(6): p. 1524-1538.
10. Chaishome, J., et al., Thermal Degradation of Flax Fibres as Potential Reinforcement in Thermoplastic Composites. Advanced Materials Research, 2014. 894: p. 32-36.

11. Chaishome, J. and S. Rakmae. Thermal Stability of Bamboo Fibres. in $7^{\text {th }}$ International Conference on Agricultural engineering (TSAE2014). 2014. Pranakhornsriayothanya, Thailand.

12. Chaishome, J. and S. Rattanapaskorn, The Influence of Alkaline Treatment of Plant Fibres on Tensile Properties of Single Fibres and Composites. Materials Science Forum, 2017. 894: p. 46-49.

13. De Rosa, I.M., et al., Morphological, thermal and mechanical characterization of okra (Abelmoschus esculentus) fibres as potential reinforcement in polymer composites. Composites Science and Technology, 2010. 70(1): p. 116-122.

14. Gassan, J. and A.K. Bledzki, Thermal degradation of flax and jute fibers. Journal of Applied Polymer Science, 2001. 82(6): p. 14171422.

15. Ouagne, P., et al., Analysis of the film stacking processing parameters for PLLA/flax fibre biocomposites. Journal of Composite Materials, 2010. 44(10): p. 1201-1215.

16. Wielage, B., et al., Thermogravimetric and differential scanning calorimetric analysis of natural fibres and polypropylene. Thermochimica Acta, 1999. 337(1â€“2): p. 169-177.

17. Pielichowski, K.N., James Rapra Technology Limited Staff, Thermal Degradation of Polymeric Materials. 2005, Shrewsbury: Smithers Rapra. 320.

18. Yao, F., et al., Thermal decomposition kinetics of natural fibers: Activation energy with dynamic thermogravimetric analysis. Polymer Degradation and Stability, 2008. 93(1): p. 9098. 